\title{
Spatiotemporal Pattern of Retinal Ganglion Cell Differentiation Revealed by the Expression of Neurolin in Embryonic Zebrafish
}

\author{
Ute Laessing and Claudia A. O. Stuermer * \\ Faculty of Biology, University of Konstanz, 78434 Konstanz, Germany
}

\section{SUMMARY}

The expression of neurolin, the fish homologue of the cell adhesion molecule DM-GRASP / BEN / SC-1, is dynamically regulated. Here we demonstrate that the expression of neurolin correlates with early events of retinal ganglion cell (RGC) differentiation in zebrafish embryos. Neurolin mRNA first appears [ $28 \mathrm{~h}$ postfertilization, (PF)] in nasoventral cells, representing the first RGCs, then in dorsal, central ( 34 to $40 \mathrm{~h} \mathrm{PF}$ ) and temporal RGCs. After differentiation of RGCs in the central portion of the retina, RGCs exhibiting neurolin mRNA form rings. These rings move toward the retinal periphery and encompass older (central) RGCs. Thereafter, such as at 3.5 days PF, neurolin mRNA expressing RGCs are confined to the annular growth zone at the retinal peripheral margin. Two hours after onset of $\mathrm{mRNA}$ expression, RGCs acquire antineurolin immunoreactivity on the surface of their somata and on their axons as they extend to the tectum. The mRNA signal in RGCs decreases significantly within $20 \mathrm{~h}$ after its appearance, which correlates with the arrival of axons in the tectum. This is followed by weakening of neurolin immunoreactivity on RGCs and axons. This pattern of RGC differentiation in zebrafish revealed by the expression of neurolin is unique among vertebrates. The spatiotemporal expression pattern of neurolin suggests a functional significance of this cell adhesion molecule in $\mathrm{RGC}$ recognition and RGC axon growth. (c) 1996 John Wiley \& Sons, Inc. Keywords: in situ hybridization, immunocytochemistry, cell adhesion molecule, RGC differentiation, regulated expression.

\section{INTRODUCTION}

The patterning of characteristic neuronal structures involves a multitude of cellular recognition and signaling events and requires the coordinated expression of molecules mediating cell-cell interactions. Cell adhesion molecules are known to participate in these events, particularly when their expression is spatially and temporally restricted (Takeichi, 1988; Williams and Barclay, 1988; Rathjen and Jessell, 1991). The retinotectal projection in zebrafish exhibits a striking degree of order even at early stages of embryonic development (Stuermer, 1988; Burrill and Easter, 1994, 1995).

Received June 28. 1995: accented August 29. 1995

\footnotetext{
* To whom correspondence should be addressed.
}

Its ongoing growth through larval development and into adulthood (Johns, 1977) obeys specific rules leading to the unique age-related order of retinal ganglion cells (RGCs) and their axons in this system (Scholes, 1979; Easter et al., 1981; Stuermer and Easter, 1984). However, the early events of retinal ganglion cell differentiation are less understood. Moreover, only a few of the many cell adhesion molecules known from other species have been characterized in zebrafish to date $(\mathrm{N}$ cadherin: Bitzur et al., 1994; neurolin: Laessing et al., 1994; DM-GRASP: Kanki et al., 1994), and their expression during retinotectal development is therefore unclear.

Neurolin is a cell adhesion molecule of the immunoglobulin $(\mathrm{Ig})$ superfamily that has been identified in goldfish and zebrafish (Paschke et al., 1992; Laessing et al., 1994). It is called zebrafish DM-GRASP by Kanki et al. ( 1994) and belongs to the DM-GRASP/BEN/SC-1 family (Burns et al., 
1991; Tanaka et al., 1991; Pourquié et al., 1992). A related molecule, irre C-rst (Ramos et al., 1993) was found in Drosophila. In chick this molecule mediates cell adhesion and promotes axon growth (Burns et al., 1991).

Using neurolin antibodies, the protein was found selectively on growing retinal axons in larval and adult goldfish and zebrafish (Paschke et al., 1992; Laessing et al., 1994). These axons derive from newborn ganglion cells at the retinal peripheral margin and cluster into age-related bundles (reviewed in Stuermer et al., 1992). New ganglion cells, but not their marginal precursors, transiently express neurolin over their entire surface, but later neurolin is restricted to cell-cell contact sites (Paschke et al., 1992). Neurolin is also down-regulated on the axonal surface but remains in the optic tectum where axons entertain contacts with tectal cells via their terminal arbors. The patterned expression of neurolin and in particular its appearance on newborn RGCs in the annular growth zone of the retina indicates that neurolin may be involved in RGC differentiation during zebrafish embryonic development.

Using neurolin cRNA probes and antibodies, we examined the spatiotemporal pattern of RGC differentiation in the embryonic zebrafish retina. The pattern of RGC recruitment from undifferented retinal cells in zebrafish is unique among vertebrates in that the first RGCs emerge in nasoventral retina. Furthermore, after differentiation of RGCs in the central portion of the retina, RGCs expressing neurolin mRNA are organized in distinct rings moving toward the retinal periphery. Neurolin protein appears shortly after onset of mRNA expression on the surface of the RGC somata, and then extends to the RGC axons emerging from these cells and migrating to the optic tectum. These data imply a function of neurolin for early events in the development of the zebrafish retinotectal projection.

\section{METHODS}

\section{Zebrafish Embryos}

Zebrafish embryos of the golden ( $g o l$ ) strain with reduced pigmentation were obtained from our breeding colony and raised at $28.5^{\circ} \mathrm{C}$ (Westerfield, 1993). They were staged prior to blastula stages and identified by hours postfertilization (PF). For studies in fish older than 2 days, embryos from $25 \mathrm{~h}$ PF onwards were raised in $0.003 \%$ 1-phenyl-2-thiourea (PTU; Sigma) to inhibit further pigmentation. This slowed their normal develop- ment notably after 4 days PF, but obviously not before this time.

\section{RNA Probes}

Riboprobes were generated using a 500 bp polymerase chain reaction (PCR) fragment coding for the C-terminus of zebrafish neurolin (Laessing et al., 1994), which was cloned into the pCRII vector of the TA cloning kit (Invitrogen).

Antisense RNA probes were transcribed in vitro from EcoRV linearized plasmid using digoxigenin-labeled recombinant uridine triphosphate and SP6 RNA polymerase according to the manufacturers' instructions (DIG RNA Labeling Kit, Boehringer). For probe quantification several dilutions of the labeled probe were dot blotted on a nylon membrane (Stratagene) and compared to a labeled DNA standard. Detection was carried out as described in the manufacturers' instructions (DIG Labeling and Detection Kit, Boehringer). Sense probes were transcribed from KpnI linearized plasmid with T7 RNA polymerase.

\section{Whole Mount in situ Hybridization}

Embryos were killed in an overdose of methane sulfonate salt, 3-aminobenzoic acid ethyl ester (MS222; Sigma), washed twice in phosphate buffered saline (PBS; Seromed Biochrom) and fixed overnight in 4\% paraformaldehyde (PFA) in PBS at $4^{\circ} \mathrm{C}$. Embryos were dechorionated and stored in methanol at $-20^{\circ} \mathrm{C}$ for at least $2 \mathrm{~h}$. Prior to hybridization, embryos were rehydrated in a graded series of methanol in PBS ( $2 \mathrm{~min})$, washed twice with PBS containing $0.1 \%$ Tween-20 (PBST), and then treated with proteinase $\mathrm{K}(80 \mu \mathrm{g} / \mathrm{ml}$; Boehringer $)$ at room temperature (RT) for 2 to $5 \mathrm{~min}$, depending on the age of the embryos. Digestion was stopped by rinsing the embryos twice in PBST, followed by fixation in $4 \%$ PFA for $20 \mathrm{~min}$ at RT. Embryos were washed in PBST (three times for $5 \mathrm{~min}$ ), and then prehybridized for $1 \mathrm{~h}$ at $65^{\circ} \mathrm{C}$ in hybridization buffer $(50 \%$ formamide, 5 $X$ saline-sodium citrate (SSC), $0.1 \%$ Tween- $20,50 \mu \mathrm{g} /$ $\mathrm{ml}$ heparin, $500 \mu \mathrm{g} / \mathrm{ml} \mathrm{t}-\mathrm{RNA}, \mathrm{pH}$ adjusted to 6.0 with citric acid). After prehybridization, antisense or sense RNA probes were added at a final concentration of 300 $\mathrm{ng} / \mathrm{ml}$. Embryos were incubated overnight at $65^{\circ} \mathrm{C}$ and gently shaken on an Eppendorf Thermomixer. After hybridization, embryos were washed while shaking, at $65^{\circ} \mathrm{C}$ in a graded series of hybridization buffer $/ 2 \times \mathrm{SSC}$ mixture (three times for $10 \mathrm{~min}$ ), followed by several washes with $2 \times \mathrm{SSC}$ ( two times for $5 \mathrm{~min}$ at $65^{\circ} \mathrm{C}$ ), $0.2 \times \mathrm{SSC}$ (two times for $30 \mathrm{~min}$ at $60^{\circ} \mathrm{C}$ ), and finally with PBST (two times for $5 \mathrm{~min}$ at $\mathrm{RT}$ ). Prior to detection, the embryos were incubated for $1 \mathrm{~h}$ in PBST at RT containing $1 \%$ bovine serum albumin (Sigma) and $2 \%$ sheep serum. On incubation in preadsorbed antidigoxigenin antibody (diluted 1:5000 in PBS) for $2 \mathrm{~h}$ at RT or $1 \mathrm{~h}$ at $37^{\circ} \mathrm{C}$, the embryos were rinsed several times with PBST over a total of $1.5 \mathrm{~h}$. Then the embryos were equilibrated in alkaline 
phosphatase detection buffer ( $100 \mathrm{~m} M$ Tris $/ \mathrm{HCl} \mathrm{pH}$ 9.5, $100 \mathrm{~m} M$ sodium chloride, $50 \mathrm{~m} M$ magnesium chloride) for $5 \mathrm{~min}$. Staining reaction was activated by adding $4.5 \mu \mathrm{l} / \mathrm{ml}$ nitro blue tetrazolium (NBT) and 3.5 $\mu \mathrm{l} / \mathrm{ml} \mathrm{X}$-phosphate (Boehringer). The development reaction was stopped by several washes in water. Stained embryos were kept in $4 \%$ PFA at $4^{\circ} \mathrm{C}$ and then dehydrated in methanol ( two times for $10 \mathrm{~min}$ ).

\section{Plastic Sections}

Following dehydration, stained embryos were transferred to a glass tube and exposed to propylene oxide (Merck; two times for $10 \mathrm{~min}$ ), to propylene oxide and Durcupan (Fluka; dilution 1:1 for $3 \mathrm{~h}$ ), and incubated overnight in $100 \%$ Durcupan at RT. Embryos were transferred to fresh Durcupan at $70^{\circ} \mathrm{C}(24 \mathrm{~h})$ for polymerization of the resin, and then sectioned ( 10 to $20 \mu \mathrm{m}$ ) on a microtome (Leica).

\section{Whole Mount Antibody Staining}

Embryos or larvae were rinsed twice with PBS and fixed in ice-cold methanol $\left(-20^{\circ}\right)$ for 5 to $8 \mathrm{~min}$, depending on the age of the fish. After rehydration in PBST, they were incubated in blocking solution (PBST, 1\% BSA, 2\% serum) for $1 \mathrm{~h}$ at RT. The primary antibodies, directed against goldfish neurolin (monoclonal $457 / \mathrm{m}$ and 441 / 3 , diluted $1: 10$, or polyclonal 397 , diluted $1: 4000$ in blocking solution) (Laessing et al., 1994), were added. In some experiments a monoclonal antibody against acetylated alpha-tubulin (clone 6-11B1; Sigma) was used (Piperno and Fuller, 1985). Embryos were incubated for $2 \mathrm{~h}$ at $37^{\circ} \mathrm{C}$ under gentle rotation and washed four times in PBST ( $10 \mathrm{~min}$ at RT), before the cyanine3 coupled secondary antibodies (donkey anti-mouse; Dianova, diluted 1:1500 in blocking solution) were added. Following incubation ( $1 \mathrm{~h}$ at $37^{\circ} \mathrm{C}$ ), embryos were rinsed over several hours in PBST (RT), to reduce unspecifically bound secondary antibodies. Specimens were stored overnight at $4^{\circ} \mathrm{C}$ in PBST and then photographed in a fluorescence microscope (Zeiss Axiophot or Leica confocal microscope CLSM TCS ${ }^{4 D}$ ). For sections, embryos were stained using the $\mathrm{ABC}$ Vectastain immunoperoxidase and DAB Substrate Kit ( Vector Laboratories, Burlingame, CA) according to the manufacturer's instructions and the zebrafish book (Westerfield, 1993), and embedded in Durcupan as described.

\section{RESULTS}

\section{Spatiotemporal Pattern of Neurolin mRNA Expression}

There are two significant features of neurolin expression in the embryonic zebrafish retina: (1) Onset of neurolin expression in retinal cells is indica- tive of RGC differentiation; and (2) high-level transcription of neurolin in individual RGCs is transient. This allows resolution of the spatiotemporal pattern of $\mathrm{RGC}$ recruitment from undifferentiated retinal cells, which by and large occurs in a centroperipheral gradient, first involving distinct groups and then rings of cells.

In situ hybridization signals with neurolin cRNA probes were first detected in the retina of embryos $28 \mathrm{~h} \mathrm{PF}$, and were confined to a small group of no more than 10 cells in the ventronasal retina, midway between the center and retinal periphery, and in the vicinity of the optic fissure [Fig. 1(A)]. That this group indeed represents the first differentiating RGCs is substantiated by a recent report by Burrill and Easter (1995) in which cells in this very same location were back-labeled from the leading front of axons in the embryonic optic nerve. Moreover, the first emerging axons identified here by their neurolin immunopositivity derived from these cells (see later). At $31 \mathrm{~h} \mathrm{PF}$, cells in the nasodorsal retina also exhibited the mRNA signal [Fig. 1(B)]. Two hours later, RGCs carrying the in situ hybridization signal formed a ragged arch of roughly $180^{\circ}$ extending from the nasoventral to dorsal retina [Fig. 1(C)]. Cells central from this arch and cells of temporal and temporoventral retina did not exhibit staining at this time. This overall early pattern of RGC differentiation is also consistent with the distribution of back-labeled RGCs described by Burrill and Easter (1995).

By $34 \mathrm{~h} \mathrm{PF}$, in situ hybridization signals were seen in the dorsocentral retina but still not in temporal retinal cells [Fig. 1(D)]. Temporoventral cells, displayed the in situ hybridization signal at 37 to $40 \mathrm{~h} \mathrm{PF}$, first in a ventral cluster in the vicinity of the optic fissure and then in cells further toward the temporal retinal pole [Fig. I (E)]. At this time, two groups of dorsal and temporal RGCs located further peripherally than the remainder of stained cells began to exhibit the in situ hybridization signal [Fig. 1(E)]. They probably represent the first of those RGCs, which a few hours later form a $360^{\circ}$ ring in the retina. Thus, most of the central retina (to roughly $30 \%$ of the retinal radius) contained neurolin mRNA-expressing RGCs at $40 \mathrm{~h}$ PF. The nasoventral and dorsocentral retinal cells, which were among the first to show the signal, lost most of the signal shortly thereafter, that is, at $48 \mathrm{~h} \mathrm{PF}$ [Fig. 1(G,F)]. This coincides temporally with the arrival of the first RGC axons in the tectum (Stuermer, 1988; Burrill and Easter, 1994).

Between 40 and $48 \mathrm{~h}$ PF, RGCs with significantly stronger staining formed a $360^{\circ}$ ring several cells wide encompassing older, more central RGCs 

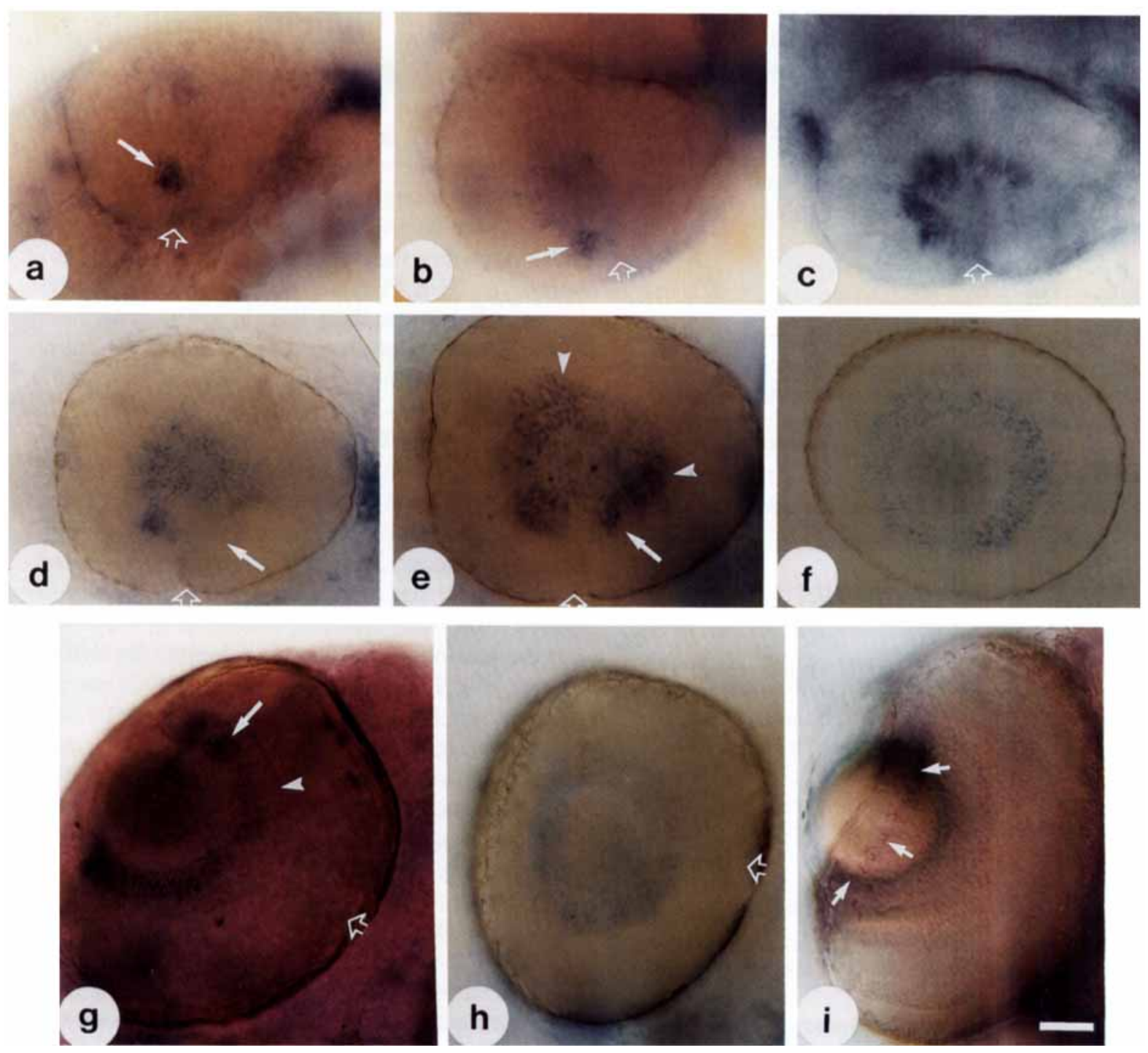

Figure 1 The spatiotemporal pattern of neurolin mRNA expression in the embryonic and larval zebrafish eye revealed by in situ hybridization. Retinas, all from left eyes, are in (A-F) oriented so that dorsal is up, ventral is down, nasal is to the left, and temporal is to the right. In (G-I) ventrolateral views of the left eye are presented. The open white arrow marks the optic fissure in ( A-E, and $\mathrm{G}, \mathrm{H}$ ). Scale bar $=80 \mu \mathrm{m}$. (A) At $28 \mathrm{~h}$ PF: in situ hybridization signal is confined to a ventronasal cluster of cells (arrow), near the optic fissure. (B) At $31.5 \mathrm{~h}$ PF: stained cells extend from the ventronasal cluster (arrow) into the dorsal retina. (C) At $33 \mathrm{~h} \mathrm{PF}$ : stained cells form a ragged arch in dorsocentral retina. (D) At $34 \mathrm{~h}$ PF: most of the central retina contains labeled cells, but cells in the temporal retina are spared (arrow). (E) At $40 \mathrm{~h}$ PF: staining extends to cells in the temporal retina (arrow) and to two groups of cells in more dorsal and temporal peripheral positions (arrowheads). ( $F, G$ ) At $48 \mathrm{~h}$ PF: parasagittal section $(F)$ and whole mount $(G)$ showing a $360^{\circ}$ ring of labeled RGCs $(F)$, between the retinal center and the periphery, only half of which is visible in $(G)$ (arrow). RGCs central to this ring ( $G$, arrowhead) have lost staining. (H) At $50 \mathrm{~h}$ PF: staining includes further peripheral RGCs, all of which are organized in a ring. (I) At $3.5 \mathrm{~d}$ PF: the in situ hybridization signal (arrows) is restricted to one row of cells at the outermost peripheral retinal margin. Scale bar $=80 \mu \mathrm{m}$.

[Fig. 1(G)]. Sections through the eyes at $48 \mathrm{~h}$ PF confirmed this pattern [Fig. 1(F)]. After $50 \mathrm{~h} \mathrm{PF}$ more of the centrally located RGCs lost the stain- ing. The ring of cells stained heavily at this time was located further out, midway between the retinal center and the periphery [Fig. $1(\mathrm{H})]$. The an- 

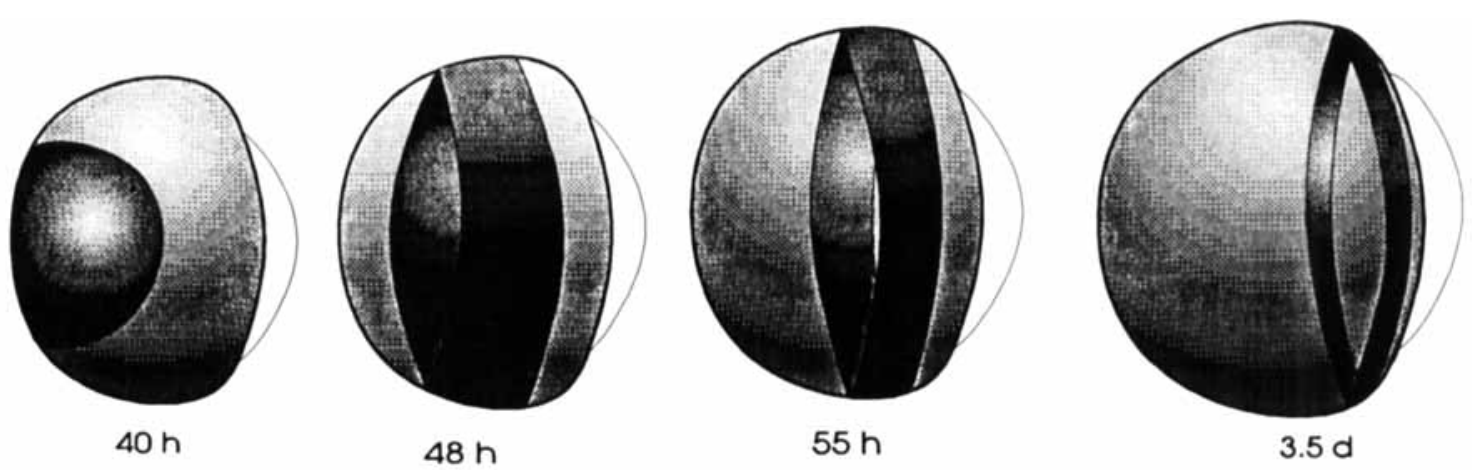

Figure 2 Schematic representation of the location of RGCs exhibiting the in situ hybridization signal (in black) in the eyes of zebrafish embryos between $40 \mathrm{~h}$ and 3.5 days PF. The white zone to the right is the lens.

nular pattern of RGCs with strong mRNA signal moved further toward the retinal periphery, whereas the eye and the retina curved increasingly. At 3.5 days PF, the annulus of cells exhibiting the in situ hybridization signal was at the outer edge of the retina. This annulus was of no more than one or two cell diameters in width [Fig. 1(I)]. From work on older fish (Paschke et al., 1992; Laessing et al., 1994), we infer that the further growth of the retina and recruitment of RGCs continues by the addition of rings similar to those seen at 3.5 days.

The spatiotemporal pattern of RGC differentiation between $40 \mathrm{~h}$ and 3.5 days $P F$ is summarized in Figure 2, to illustrate the position of rings of mRNA expressing RGCs.

\section{Expression of Neurolin Protein on Retinal Ganglion Cells and Their Axons}

The transient intense expression of neurolin mRNA in RGCs was followed by the appearance and subsequent decrease of neurolin protein on the RGC somata and axons as revealed by immunocytochemistry with antineurolin antibodies.

Two to $3 \mathrm{~h}$ after the appearance of the in situ hybridization signal, RGCs of the nasoventral cluster (at $31.5 \mathrm{~h} \mathrm{PF}$ ) were labeled by neurolin antibodies [Fig. 3(A,B)]. The first axons identified by their label derived from this cluster of cells in embryos $32 \mathrm{~h}$ old and extended along the fissure [Fig. 3 (A,B)]. A few hours later ( $34 \mathrm{~h} \mathrm{PF}$ ) neurolin labeling was seen in RGCs in dorsal and then central retina and included axons extending into the optic stalk and toward the tectum [Fig. 3(C)]. The first as well as subsequent RGC axons were only weakly stained by anti-alpha-tubulin antibodies (Piperno and Fuller, 1985), suggesting that neurolin expression on growing RGC axons is more pronounced than this cytoskeletal protein. Immunolabeling in- creased on the ventronasal, dorsal, and central RGCs at $38 \mathrm{~h} \mathrm{PF}$, whereas RGCs of ventrotemporal retina began to exhibit surface labeling later, as clearly seen at $44 \mathrm{~h}$ PF [Fig. 3(E)]. After most RGCs of the central portion of retina had become immunopositive, a group of ventrotemporal RGCs reaching further peripherally acquired label at $46 \mathrm{~h}$ PF [Fig. 3(F)]. This group of RGCs later becomes presumably part of the first ring of neurolin-positive RGCs.

At $48 \mathrm{~h}$ PF cells in further peripheral retinal positions and grouped into a ring were more heavily labeled than their more central counterparts [Fig. $3(\mathrm{G})$ ]. The peripheral extreme of retina, however, was still unlabeled at this time. This was confirmed by sections through retinas that were subjected to immunostaining procedures with an horseradish peroxidase (HRP)-coupled secondary antibody [Fig. 3(H)]. They showed weak surface staining of more central RGCs and intense reaction product on the more peripherally located RGCs, whereas the zone closest to the retinal margin was unlabeled [Fig. 3(H)]. These sections also showed that the radial extent of differentiated retinal tissue was greater in dorsal retina than in ventral retina, taking the optic nerve head as the point of reference (Marsh-Armstrong et al., 1994). These differences in retinal extent were more evident in sections than in the whole mounts. The sections also revealed stain on axons leaving the eye [Fig. 3(H)]. Later on, RGCs with intense neurolin immunoreactivity were found selectively at the retinal peripheral margin, much as RGCs with in situ hybridization signal [Fig. 1(I)], and as illustrated by a retina at 5-day PF [Fig. 3(I)].

Labeled RGC axons were observed at their origin [Fig. 3(A-I)], in the optic nerve [Fig. $3(E, F, G)]$, and in the contralateral optic tectum, where they arrive at 46 to $48 \mathrm{~h} \mathrm{PF}$ (Stuermer, 

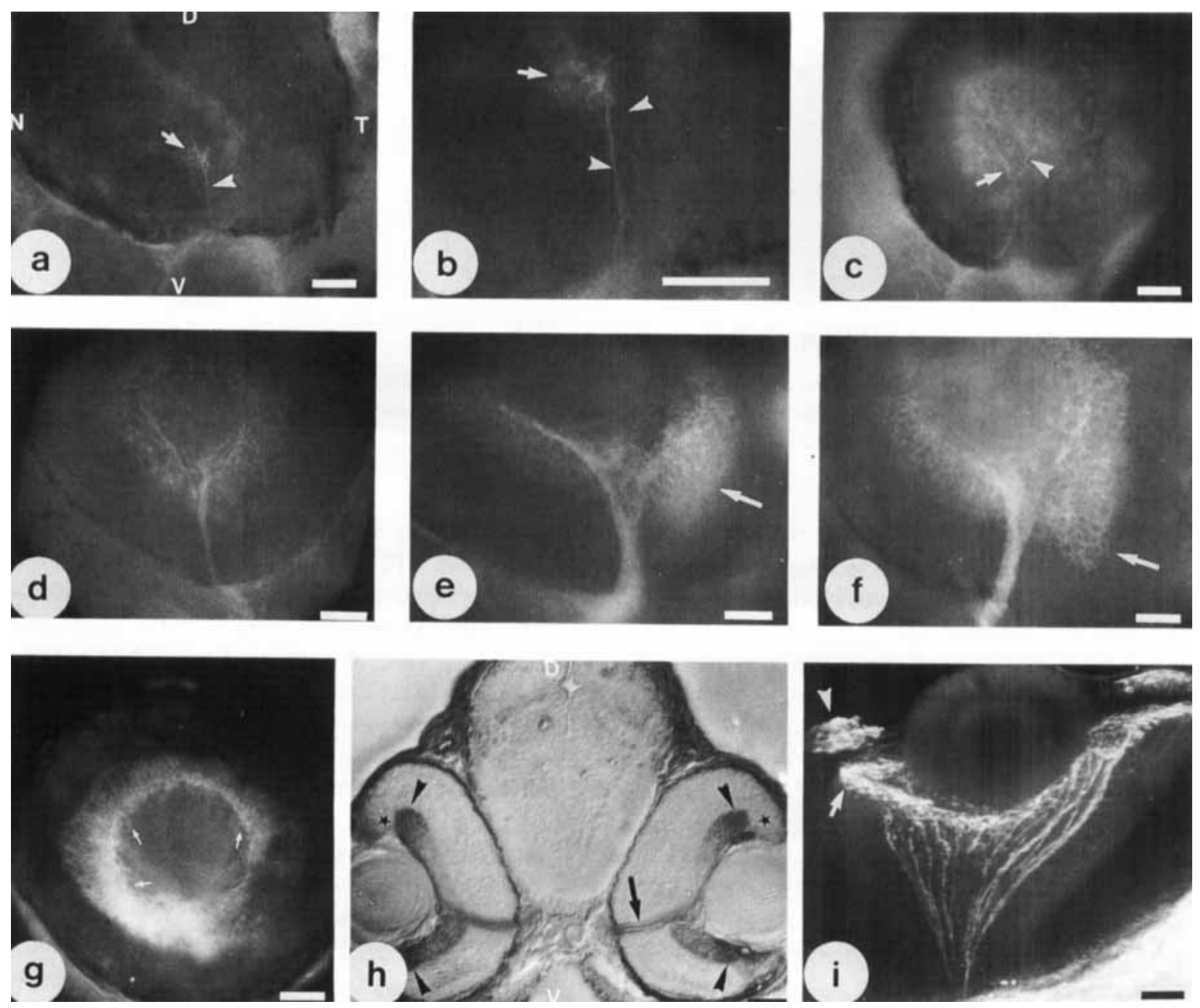

Figure 3 The spatiotemporal pattern of neurolin protein expression in the developing zebrafish eye revealed by immunohistochemistry with monoclonal antibodies $441 / 3$ and $457 / \mathrm{m}$. Abbreviations: $\mathrm{N}$, nasal; $\mathrm{T}$, temporal; V, ventral; D, dorsal. Scale bars $=25 \mu \mathrm{m}$. (A) At $32 \mathrm{~h}$ PF: RGCs of the ventronasal cluster [arrow; compare Fig. 1(a)] and axons originating from these cells (arrowhead) are antineurolin immunoreactive. The axons travel ventrally, along the optic fissure. (B) Higher magnification of RGCs (arrow) and axons (arrowheads) shown in (A). (C) At $34 \mathrm{~h}$ PF: staining includes RGCs and axons of nasal (arrow), some of dorsocentral, and a few of central retina (arrowhead), but temporal retina is spared. (D) At $38 \mathrm{~h}$ PF: RGCs and axons of dorsal and central retina exhibit staining. (E) At $44 \mathrm{~h}$ PF: In addition to nasal, dorsal, and central RGCs, labeling extends to temporal cells at this stage (arrow). (F) At $46 \mathrm{~h}$ PF: stained RGCs of temporal retina extend further peripherally (arrow) than the remainder of the RGCs. (G) At $48 \mathrm{~h}$ PF: labeled RGCs are organized in a ring around central cells, which have reduced their surface labeling. Axons (arrows) deriving from these labeled cells (here slightly out of focus) project into the optic nerve. (H) At $50 \mathrm{~h}$ PF transverse plastic section of a whole mount (HRP-diaminobenzidine reaction product): RGCs in ventral and dorsal peripheral retina (arrowheads) and RGC axons in the optic nerve (arrow) exhibit neurolin staining on their surface. *Unlabeled undifferentiated cells, peripheral to labeled RGCs. (I) Confocal image of a 5-day PF retina, lateral view: cells at the retinal margin form a ring at the outermost periphery of the retina (arrow). The iris (arrowhead) is also stained.

1988; Easter and Burrill, 1995). In embryos at 74 h PF, labeling was apparently associated with all axons in the optic nerve and discernible as these axons enter the tectum.
Staining of most RGC axons on their path to and through the tectum weakened subsequently. However, RGC axons from brightly labeled peripheral RGCs were always discernible by their in- 

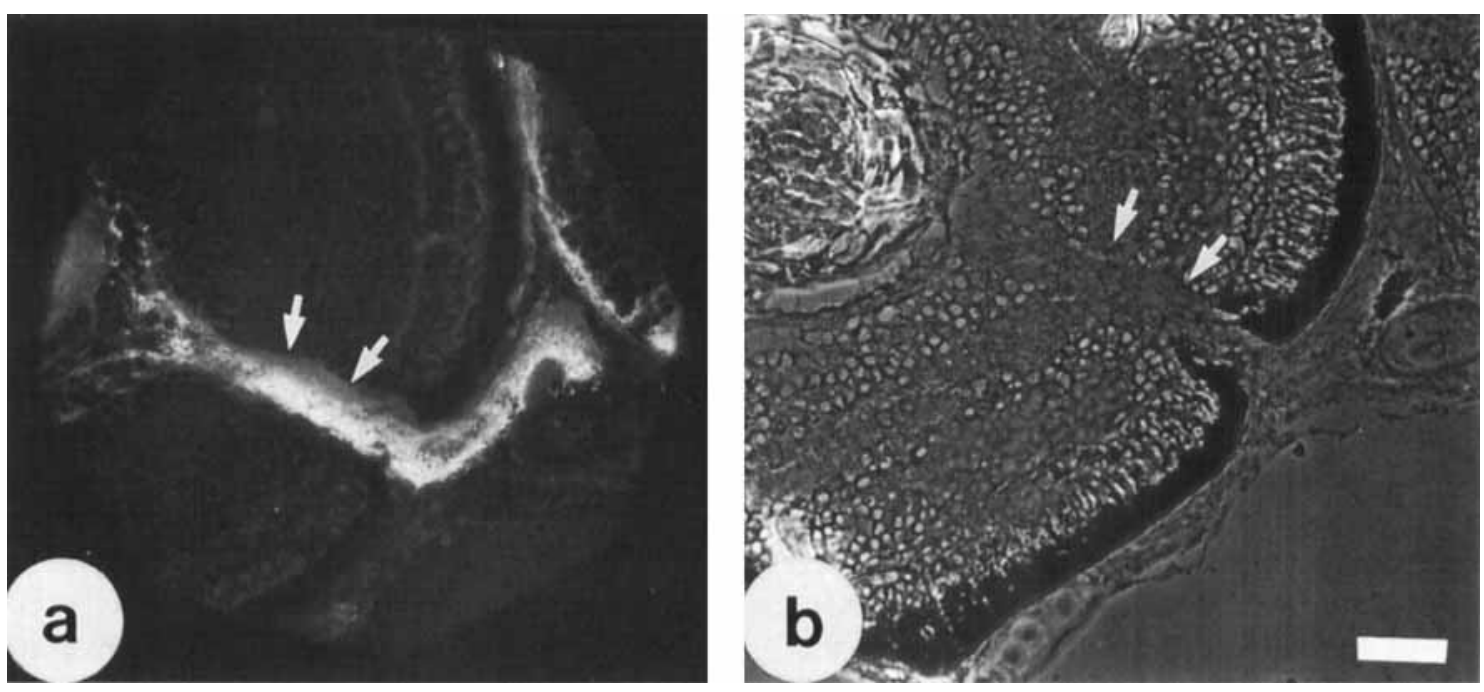

Figure 4 Transverse section showing the optic nerve exit of a 6-day-old zebrafish stained with the monoclonal antineurolin antibody $441 / 3$. Scale bar $=25 \mu \mathrm{m}$. (A) RGC axons (arrows), running dorsally in the optic nerve, exhibit weaker neurolin immunoreactivity than the younger RGC axons in the ventral part of the optic nerve. (B) Phase contrast of (A).

tense neurolin immunoreactivity in older fish [Fig. $3(\mathrm{I})]$. This is also demonstrated by a section through the eye and optic nerve from a 6-day PF zebrafish. RGC axons in the ventral aspect of the nerve are brightly labeled, whereas those more dorsally are weakly stained [Fig. 4(A)]. This reflects an early state of the age-related organization of RGC axons, which is typical of the fish retinotectal pathway (Easter et al., 1981; Scholes, 1989; Stuermer et al., 1992).

\section{DISCUSSION}

In this study we have analyzed the pattern of RGC differentiation with probes revealing the expression of the cell adhesion molecule neurolin. The onset of neurolin mRNA expression in retinal cells identifies differentiating RGCs in zebrafish embryos. This and the fact that high level expression of neurolin mRNA and protein in RGCs is transient permits a visualization of the pattern of RGC recruitment. This pattern has not been seen in other vertebrates. It is unique in that nasoventral RGCs differentiate prior to those in dorsal, temporal, and ventrotemporal retina, and in that subsequently differentiating RGCs are organized in outwardly moving rings.

The appearance of the first RGCs in the ventronasal retina, revealed here by neurolin expression at $28 \mathrm{~h} \mathrm{PF}$, is consistent with findings by Nawrocki (1985) who identified differentiating RGCs by morphological criteria. RGCs extend axons shortly after acquisition of their cell identity (Halfter et al., 1985). Although the very first RGC axons were hardly detectable by anti-alpha-tubulin antibodies (Piperno and Fuller, 1985), they were identified here by their neurolin immunoreactivity and derived from the ventronasal cluster of neurolin-expressing RGCs. This, together with recent evidence by Burrill and Easter (1995) that ventronasal RGCs are the origin of the first axons in the retina supports the present claim that neurolin expression by retinal cells is indicative of $R G C$ differentiation.

In other vertebrates, RGC differentiation (Sidman, 1961; Robinson, 1987; Rager et al., 1993; Reese et al., 1994) and axogenesis from RGCs commences in the dorsocentral retina (Grant and Rubin, 1980; Silver and Sapiro, 1981; Halfter et al., 1985 ) and spreads diffusely toward the periphery. Distinct rings have not been reported. Earlier studies proposed that temporal RGCs in fish and amphibians send axons into the tectum and differentiate prior to nasal RGCs (reviewed by Gaze, 1970 ). Such a sequence of axogenesis and axonal invasion into tectum would account for the development of the retinotopic order of axons in the tectum, but these ideas have meanwhile been disputed (Walter et al., 1987; Stuermer, 1988; Kaethner and Stuermer, 1992). In fact, as shown in the present study, temporal RGCs in zebrafish differentiate hours after their nasal counterparts. Since axons from the first differentiated RGCs are the first in the optic nerve (here and Burrill and Easter, 1995), 
they are probably also the first to arrive at the tectum. They certainly are among the first to invade and progress through the tectum (Kaethner and Stuermer, 1992).

Although RGC differentiation in fish proceeds gradually from the central to the peripheral retina, as in most vertebrates studied so far, the progression in rings is unique. The differentiation of RGCs in rings anticipates the well-known annular growth at the peripheral margin of both goldfish and zebrafish retinas, which continues into adulthood (Johns, 1977; Laessing et al., 1994). Although the annular growth in the periphery of the retina in older fish is obvious - the periphery is the zone where precursors of retinal neurons persist (Johns, 1977) - it was unexpected to find these rings in the embryonic eye, prior to the additive growth at the retinal margin, as for instance at 48 and $50 \mathrm{~h} \mathrm{PF}$. At this stage, the prospective retina is filled over its entire extent with cells all exhibiting a similar undifferentiated morphology (Nawrocki, 1985). Although several transcription factors and segmentation genes were identified in the zebrafish retina in the recent past (for instance, pax-6, Püschel et al., 1992; wnt 10a, Kelly et al., 1993; seven-up, hlx-1, Fjose et al., 1993, 1994; islet-1, Korzh et al., 1993; axial, Strähle et al., 1993; Radar, Rissi et al., 1995) we are not aware of any that could account for this early annular pattern. Recently, a nuclear oncoprotein, $v$-rel, was discovered that induces expression of DM-GRASP, the avian homolog of fish neurolin in tumor cells (Zhang et al., 1995). It will be interesting to see whether a related protooncogene exists in zebrafish and regulates neurolin expression during embryogenesis and subsequent larval life.

The distribution of neurolin may indicate that this molecule mediates $\mathrm{RGC}-\mathrm{RGC}$ recognition and perhaps contributes to their assembly and laminar order in the RGC layer. This is supported by the transient expression of neurolin in the entire circumference of the RGC somata. E 587 antigen, another fish cell adhesion molecule of the Ig superfamily, is in contrast to neurolin selectively expressed on the surface of the RGC axons (Vielmetter et al., 1991). However, the presence of neurolin on RGC axons and growth cones during their migration through the optic nerve and into the tectum suggests a further function, that is, in axonal growth as has been demonstrated for its chick homologue (Burns et al., 1991, Pollerberg and Mack, 1994).

High-level expression of neurolin mRNA in RGCS is transient, as is the presence of protein on the RGC somata and RGC axons. Thus, high-level expression of neurolin in the embryonic retina is restricted to a narrow time window in which RGCs undergo decisive steps in their development, such as acquisition of cell identity and extension of their axons. The temporal correlation between arrival of the leading front of RGC axons in the tectum (Stuermer, 1988; Burrill and Easter, 1994) and down-regulation of neurolin message and protein from central RGCs suggest the possibility that axonal contact with target cells is involved in downregulation. The present method of revealing neurolin mRNA suggests that high-level expression prior to down-regulation lasts less than $20 \mathrm{~h}$. However, observation of RGCs that have ceased highlevel expression as seen in adult fish (Paschke et al, 1992 ) still exhibit neurolin protein at RGC contact sites. Moreover, it was observed to be associated with RGC axon terminal arbors in tectum long after mRNA down-regulation (Paschke et al., 1992). This speaks for an ongoing production of mRNA in RGCs at a level that is below detection by the present method (Godsave et al., 1994).

In adult goldfish and zebrafish, neurolin and other growth-associated cell surface proteins (reviewed in Stuermer et al., 1992) are seen on young axons from newborn RGCs at the retinal margin. However, unlike E 587 antigen, a member of the L1 family (Vielmetter et al., 1991) or neural cell adhesion molecule (Bastmeyer et al., 1990), expression of neurolin on axons in the eye and optic nerve is short-lived. E 587 antigen has been shown to contribute significantly to RGC axon fasciculation and growth (Bastmeyer et al., 1995). The present results on neurolin expression will allow the performance of functional assays with antibodies and antisense probes to determine the role of this cell adhesion molecule in the developing zebrafish retinotectal pathway.

We thank Prof. Dr. K.-F. Fischbach and his group for helping with the confocal imaging. We also thank A.-Y.Loos for taking care of the zebrafish breeding colony and for the cryostate section in Figure 5, and U. Weiland, who helped sectioning the HRP/diaminobenzidine stained whole mounts. We thank M. A. Cahill and S. Giordano for reading a previous version of the manuscript. This work was supported by grants of the DFG, SFB 156; TPC6 to C.A.O.S.

\section{REFERENCES}

Bastmeyer, M., Schlosshauer, B., and Stuermer, C. A. O. (1990). The spatiotemporal distribution of $\mathrm{N}-\mathrm{CAM}$ in the retinotectal pathway of adult goldfish 
detected by the monoclonal antibody D3. Development 108:299-311.

BASTMEYER, M., LEPPERT, C., OTT, H., and STUERMER, C. A. O. (1995). Fish E 587 antigen, a number of the L1-family of cell adhesion molecules, participates in axonal fasciculation and the age-related order of ganglion cell axons in the goldfish eye. $J$. Cell Biol. 130: 969-976.

Bitzur, S., KAM, Z., and GelGer, B. (1994). Structure and distribution of $\mathrm{N}$-cadherin in developing zebrafish embryos: morphogenetic effects of ectopic overexpression. Dev. Dyn. 201:121-126.

Burns, F. R., KanNen, S. von, GuY, L., RAPER, J. A., KAMHOLZ, J., and CHANG, S. (1991). DM-GRASP, a novel immunoglobulin superfamily axonal surface protein that supports neurite extension. Neuron 7: 209-220.

Burrill, J. D. and Easter, S. S. (1994). Development of the retinofugal projections in the embryonic and larval zebrafish, (Brachydanio rerio). J. Comp. Neurol. 346, 583-600.

Burrill, J. D. and EASTER, S. S. (1995). The first retinal axons and their microenvironment in zebra-fish: cryptic pioneers and the pre-tract. $J$. Neurosci. 15: 2935-2947.

Easter, S. S., JR., Rusoff, A. C., and Kish, P. E. (1981). The growth and organization of the optic nerve and tract in juvenile and adult goldfish. $J$. Neurosci. 1:793-811.

Fjose, A., Nornes, S., Weber, U., and Mlodzik, M. (1993). Functional conservation of vertebrate sevenup related genes in neurogenesis and eye development. EMBO J. 12:1403-1414.

Fjose, A., JzPISUA-Belmonte, J., Fromental-RAMAIN, C., and DUBAULE, D. (1994). Expression of the zebrafish hlx-1 in the prechordal plate and during CNS development. Development 120:71-81.

GAZE, R. M. (1970). The formation of nerve connections. Academic Press, New York, pp. 118-171.

Godsave, S., Dekker, E.-J., Holling, T., Pannese, M., Boncinelli, E., and Durston, A. (1994). Expression pattern of Hoxb genes in the Xenopus embryo suggest roles in anteroposterior specification of the hindbrain and in dorsoventral patterning of the mesoderm. Dev. Biol. 166:465-476.

GRANT, P. and RUBIN, E. (1980). Ontogeny of the retina and optic nerve in Xenopus laevis II. Ontogeny of the optic fiber pattern in the retina. J. Comp. Neurol. 189:671-698.

Halfter, W., Deiss, S., and Schwarz, U. (1985). The formation of the axonal pattern in the embryonic avian retina. $J$. Comp. Neurol. 232:466-480.

JoHNS, P. A. (1977). Growth of the adult goldfish eye: III. Source of the new retinal cells. J. Comp. Neurol. 176:343-357.

KaEthner, R. and Stuermer, C. A. O. (1992). Dynamics of terminal arbor formation and target approach of retinotectal axons in living zebrafish embryos: a time-lapse study of single axons. $J$. Neurosci. 12:3257-3271.
KAethner, R. and Stuermer, C. A. O. (1994). Dynamics of dendrite development in the optic tectum at live zebrafish embryos. Soc. Neurosci. Abstr. 20:1081.

Kanki, J. P., Chang, S., and Kuwada, J. (1994). The molecular cloning and characterization of potential chick DM-Grasp homologs in zebrafish and mouse. $J$. Neurobiol. 25:831-845.

KelLy, G. M., LAI, C.-J., and MoON, R. T. (1993). Expression of Wnt 10a in the central nervous system of developing zebrafish. Dev. Biol. 158:113-121.

KorzH, V., EdLund, T., and THOR, S. (1993). Zebrafish primary neurons initiate expression of the LIM homodomain protein Isl-1 at the end of gastrulation. Development 118:417-425.

Laessing, U., Giordano, S., STeCher, B., LotTsPEICH, F., and StUERMER, C. A. O. (1994). Molecular characterization of fish neurolin: a growth-associated cell surface protein and member of the immunoglobulin superfamily in the fish retinotectal system with similarities to chick protein DM-GRASP/SC-1 / BEN. Differentiation 56:21-29.

Marsh-Armstrong, N., MCCAFFEY, P., Gilbert, W., DOWLING, J. E., and DRÄGER, U. C. ( 1994). Retinoic acid is necessary for development of the ventral retina in zebrafish. Proc. Natl. Acad. Sci. USA 91:72867290.

NAWrockI, L. W. (1985). Development of the neural retina in the zebrafish, Brachydanio rerio. $\mathrm{Ph} . \mathrm{D}$. thesis, University of Oregon, Eugene, OR.

PAschKe, K. A., LotTsPeich, F., and Stuermer, C. A. O. (1992). Neurolin, a cell surface glycoprotein on growing retinal axons in the goldfish visual system, is reexpressed during retinal axonal regeneration. $J$. Cell. Biol. 117:863-875.

Piperno, G. and Fuller, M. T. (1985). Monoclonal antibody specific for an acetylated form of alpha-tubulin recognize the antigen in cilia and flagella from a variety of organisms. J. Cell Biol. 101:2085-2094.

PollerberG, G. E. and MACK, T. (1994). Cell adhesion molecule SC1/DM-GRASP is expressed on growing axons of retinal ganglion cells and is involved in mediating their extension on axons. Dev. Biol. 165: 670-687.

Pourquié, O., Corbel, C., Le Caer, J.-P., Rossier, J., and LE DOUARIN, N. M. (1992). BEN, a surface glycoprotein of the immunoglobulin superfamily, is expressed in a variety of developing systems. Proc. Natl. Acad. Sci. USA 89:5261-5262.

Püschel, A. W., Gruss, P., and Westerfield, M. (1992). Sequence and expression pattern of pax-6 are highly conserved between zebrafish and mice. Development 114, 643-651.

Rager, M., Rager, G., and Frei, B. (1993). Central retinal area is not the site where ganglion cells are generated first. J. Comp. Neurol. 334:529-544.

Ramos, R. G. P., IGloi, G. L., Lichte, B., BaumanN, U., MAIER, D., SCHNEIDER, T., BRANDSTÄTTER, H., FröHLICH, A., and FISCHBACH, K. F. (1993). The irregular chiasm $\mathrm{c}$ - roughest locus of Drosophila, which affects axonal projections and programmed cell death, 
encodes a novel immunoglobulin-like protein. Genes Dev. 7:2533-2547.

Rathjen, F. G. and Jessell, T. M. (1991). Glycoproteins that regulate the growth and guidance of vertebrate axons: domains and dynamics of the immunoglobulin/fibronectin type III subfamily. Semin. Neurosci. 3:297-307.

Reese, B. E., Thompson, B. E., and Peduzzi, J. D. (1994). Birthdates of neurons in the retinal ganglion cell layer of the ferret. J. Comp. Neurol. 341:464-476.

Rissi, M., WitTbrodt, J., DÉlot, E., NAEGEli, M., and ROSA, F. M. (1995). Zebrafish radar: a new member of the TGF- $\beta$ superfamily defines dorsal regions of the neural plate and the embryonic retina. Mech. Dev. 49: 223-234.

RoBinson, S. R. (1987). The area centralis is the focal point of retinal development in the cat. Proc. Aust. Physiol. Soc. 16:232 P.

SCHOLES, J. (1979). Nerve fibre topography in the retinal projection to the tectum. Nature 278:620-624.

SIDMAN, R. L. (1961). Histogenesis of mouse retina studied with thymidine $\mathrm{H}^{3}$. In: (ed): Structure of the Eye. G. K. Smelser, Ed. Academic Press, New York, pp. 487-506.

Silver, J. and SAPIRO, J. ( 1981 ). Axonal guidance during development of the optic nerve: the role of pigmented epithelia and other extrinsic factors. J. Comp. Neurol. 202:521-538.

Strähle, U., BLADER, P., Henrique, D., and INGHAM, P. W. (1993). Axial, a zebrafish gene expressed along the developing body axis, shows altered expression in cyclops mutant embryos. Genes Dev. 7:1436-1446.

STUERMER, C. A. O. (1988). Retinotopic organization of the developing retinotectal projection in the zebrafish embryo. J. Neurosci. 8:4513-4530.

Stuermer, C. A. O. and EASTER, S. S. (1984). Rules of order in the retinotectal fascicles of goldfish. $J$. Neurosci. 4:1045-1051.

Stuermer, C. A. O., Bastmeyer, M., Baehr, M., STrobel, G., and PASCHKe, K. (1992). Trying to understand axonal regeneration in the CNS of fish. $J$. Neurobiol. 23:537-550.

TAKEICHI, M. (1988). The cadherins: cell-cell adhesion molecules controlling animal morphogenesis. Development 102:639-655.

Tanaka, H., Matsui, T., Agata, A., Tomura, M., Kubota, I., McFarland, K. C., Kohr, B., LEE, A., Phillips, H. S., and Shelton, D. L. L. (1991). Molecular cloning and expression of a novel adhesion molecule SC1. Neuron 7:535-545.

Vielmetter, J., LotTSPeich, F., and StUermer, C. A. O. (1991). The monoclonal antibody E 587 recognizes growing (new and regenerating) retinal axons in the goldfish retinotectal pathway. J. Neurosci. 11: $3581-3593$.

Walter, J., Kern-Veits, B., Huf, J., Stolze, B., and BONHOEFFER, F. (1987). Recognition of position-specific properties of tectal cell membranes by retinal axons in vitro. Development 101:685-696.

Westerfield, M. (1993). The Zebrafish Book. University of Oregon Press, Eugene, Oregon.

Williams, A. F. and BarClay, A. N. (1988). The immunoglobulin superfamily - domains for cell surface recognition. Annu. Rev. Immunol. 6:381-405.

Zhang, G., Slaughter, C., and Humphries, E. H. (1995). v-rel induces ectopic expression of an adhesion molecule, DM-GRASP, during B-lymphoma development. Mol. Cell. Biol. 15:1806-1816. 